\title{
Statistical downscaling of daily rainfall for hydrological impact assessment
}

\author{
$\underline{\text { Guobin Fu }}^{\text {a }}$, S.P. Charles ${ }^{a}$, F.H.S. Chiew ${ }^{b}$ and Jin Teng ${ }^{b}$ \\ ${ }^{a}$ CSIRO Water for a Healthy Country Flagship and CSIRO Land and Water, Private Bag 5, Wembley, \\ Western Australia; ${ }^{b}$ CSIRO Water for a Healthy Country Flagship and CSIRO Land and Water, GPO Box \\ 1666, Canberra, Australian Capital Territory \\ Email: Guobin.Fu@,csiro.au
}

\begin{abstract}
Water resource management and planning increasingly need to incorporate the effects of global climate change on regional climate variability in order to accurately assess future water supplies. Therefore future climate projections, particularly of rainfall, are of utmost interest to water resource management and water-users. General circulation models (GCMs) are the primary tool used to simulate present climate and project future climate. The outputs of GCMs are useful in understanding how future global climate responds to prescribed greenhouse gases emission scenarios. However GCMs do not provide realistic daily rainfall at scales below about $200 \mathrm{~km}$, at which hydrological processes are typically assessed. Statistical downscaling techniques have been developed to resolve the scale discrepancy between GCM climate change scenarios and the resolution required for hydrological impact assessment, based on the assumption that large-scale atmospheric conditions have a strong influence on local-scale weather. Gridded rainfall is important for a variety of scientific and engineering applications, including climate change detection, the evaluation of climate models, the parameterization of stochastic weather generators, as well as assessment of climate change impacts on regional hydrological regimes and water availability, whereas statistical downscaling has predominantly provided daily rainfall series at the site (point) scale.
\end{abstract}

This study explores the application of statistical downscaling to gridded and catchment rainfall datasets using three methods: 1) statistically downscaling to sites and then post-processing to interpolate to gridded rainfall; 2) treating each grid cell as an "observed" site for statistical downscaling directly; and 3) treating each subcatchment as an "observed" site and statistically downscaling to sub-catchment averaged rainfall. The statistical downscaling Nonhomogeneous Hidden Markov Model (NHMM), which models multi-site patterns of daily rainfall as a finite number of 'hidden' (i.e. unobserved) weather states, is used for a study region comprising several catchments of the southern Murray-Darling Basin (MDB) in south-eastern Australia, which until this year has been experiencing a decade long drought.

The results show that: 1) the best performance, of the methods compared, resulted from calibration to meteorological station data. The NHMM calibrated to 38 stations across the lower MDB reasonably reproduced the validation period mean rainfall characteristics; 2) Calibration to catchment average rainfall, for a corresponding set of 38 sub-catchments, produced a reasonable calibration result but significantly more bias for the validation period in comparison with the station NHMM results. Whether the threshold used to define wet-days influences this aspect of performance will be investigated in future work; 3) Calibration to all 364 grid cells across the study area catchments produced a biased result for both calibration and validation periods. Given this, subsequent calibration to grid cells for 12 smaller sub-catchments produced mixed results given numerical instabilities in the NHMM optimization algorithms; and 4) It is difficult to determine the relative contribution to validation-period bias that could be the result of several factors, such as inadequate parameterizations of the NHMMs, non-stationary in the relationship between NNR predictors and rainfall data, or data quality limitations. Most probably all are involved to some extent, and so future work should also investigate validation issues.

Keywords: Statistical downscaling, Murray-Darling Basin (MDB), Nonhomogeneous Hidden Markov Model (NHMM), General circulation models (GCMs) 


\section{INTRODUCTION}

Water resource management and planning increasingly need to incorporate the effects of global climate change and variability in order to accurately predict future supplies (Fu et al. 2007). Therefore future climate, particularly rainfall, is of utmost interest to resource management, agriculture, and water-users. General circulation models (GCMs), mathematical models of the general circulation of the planetary atmosphere and ocean are the primary, if not only, tool to simulate present climate and project future climate (Christensen et al., 2007). The outputs of GCMs can be useful in understanding future global climatic changes given a greenhouse gases emission scenario. However, they currently do not provide reliable information on scales below about $200 \mathrm{~km}$ (Meehl et al., 2007), on which hydrological processes typically occur (Kundzewicz et al., 2007). Therefore, higher-resolution scenarios are required for the most relevant meteorological variables to investigate the impacts of climate change on hydrological process and water availability.

Downscaling techniques have been developed to resolve the scale discrepancy between GCM climate change scenarios and the resolution required for impact assessment. Statistical downscaling, relating large-scale GCM fields to daily precipitation at observed meteorological sites, is widely used for this kind application (Maraun et al., 2010). However, gridded rainfall is also important for a variety of scientific and engineering applications, including climate change detection, the evaluation of climate models, the parameterization of stochastic weather generators, as well as assessment of climate changes on regional hydrological regimes and water availability (Hofstra et al., 2008) whereas statistical downscaling has predominantly been applied at the site (point) scale. The objective of this study is to provide a preliminary exploration of the potential for statistical downscaling to gridded rainfall datasets using the Nonhomogeneous Hidden Markov Model (NHMM) downscaling technique as described in section 2.3.

\section{MATERIALS AND METHODS}

\subsection{Study Region}

The study region comprises several catchments of the southern Murray-Darling Basin (MDB) in southeastern Australia (Fig 1), i.e., Loddon, Avoca, Campaspe, and Goulburn rivers. This region is of interest because: 1) The southern MBD produces the majority of MDB streamflow and the streamflow elasticity in the last decade is larger than the long-term average, indicating that the system is undergoing a change in its hydrological response to climate. For example, the long-term rainfall elasticity of runoff for the southern MDB is 2.16, which implies that a rainfall reduction of $10 \%$ would, on average, translate into a runoff reduction of $21.6 \%$ (Chiew et al 2006). However, the 1997-2006 drought period has an elasticity about $50 \%$ greater than the long-term average (Potter et al., 2010). 2) The NHMM has previously been applied to this region (Frost et al. 2011; Fu and Charles, 2011) where it was assessed as performing well compared to two other stochastic downscaling methods (GLIMCLIM and MMM-KDE, see Frost et al. 2011 for further details)..

\subsection{Datasets}

Three types of daily data are used in this study: (a) historical

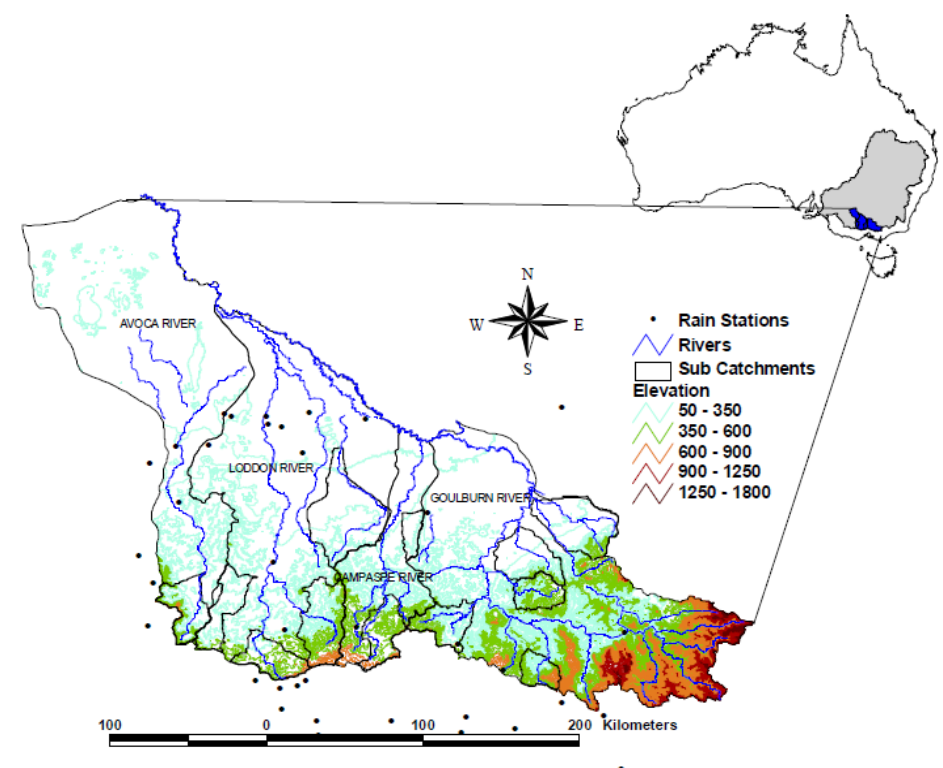

Figure 1 Study Region and climate stations.

rainfall data at meteorological stations; (b) historical rainfall data interpolated to grid cells; and (c) large spatial-scale reanalysis atmospheric predictors which are used with (a) and (b) for calibration and verification of the statistical downscaling model for sites and grid cells, respectively. 
The 38 daily rainfall stations chosen for this study are located in the southern MDB in south-eastern Australia. They come from the Patched point dataset (PPD), which uses original Bureau of Meteorology (BoM) measurements for the individual meteorological stations, with interpolated data used to fill (patch) any gaps in the observation record. The stations used in the study were selected based on having: a) continuous observations from 1961 to 2000 with less than 5\% missing data within each decade; and b) minimal untagged accumulations (as identified through the method of Viney and Bates, 2004). The elevations of the sites range from 30 to 600 meters above sea level, with annual mean rainfall (1961-2000) from 360 to $1400 \mathrm{~mm}$ (Figure 1). Of the 38 stations, 37 have less than $1 \%$ of missing data for the 40 year study period, with the only exception being Station 80019 , which has $1.42 \%$ missing data.

The SILO Data Drill data provides surfaces of daily rainfall, as well as other climate variables, interpolated to $0.05^{\circ}$ grids across Australia from point measurements made by the Australian Bureau of Meteorology through the method of Jeffrey et al. (2001), i.e., the interpolations are calculated using splining and kriging techniques. The data in the Data Drill are all interpolated with no original meteorological station data remaining. This gives the Data Drill the advantage of being available for any set of $0.05^{\circ}$ coordinates in Australia (Jeffrey et al., 2001). There are 364 grid cell rainfall series used in this study in 12 sub-catchments. The number of grids cells within each sub-catchment varies from 11 to 65 depending on sub-catchment size s. The sizes (and colours) in Figure 2 represent the magnitudes of annual rainfall for these cells.

The atmospheric predictors for the observed period were extracted as daily values from the NCEP/NCAR Reanalysis (NNR) data archive on a $2.5^{\circ} \times 2.5^{\circ}$ grid for 6 × 5 NNR grid cells over the study region (Frost et al. 2011).

\subsection{NHMM}

The NHMM was selected to downscale atmospheric

predictors to multisite daily rainfall. Previously the NHMM has been found suitable when applied to southwest Western Australia for historical (Hughes et al., 1999; Charles et al., 1999, 2004) and climate change studies (Bates et al., 1998).

The NHMM models multi-site patterns of daily rainfall as a

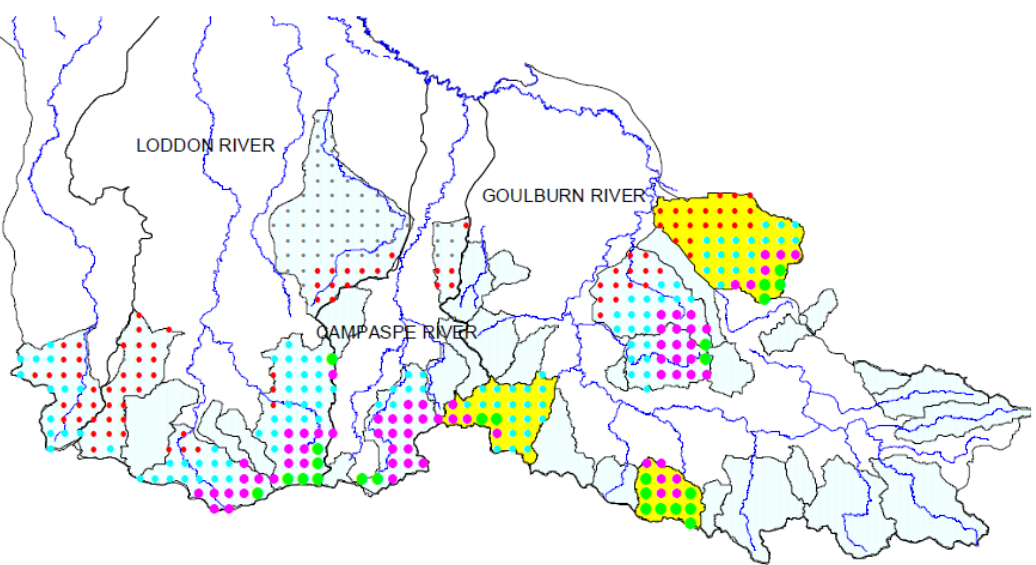

Figure 2 SILO $0.05^{\circ}$ grid rainfall (364) and 12/38 sub-catchments used in this study.

finite number of "hidden" (i.e. unobserved) weather states. The temporal evolution of these daily states is modelled as a first-order Markov process with state-to-state transition probabilities conditioned on a small number of synoptic-scale atmospheric predictors, such as sea-level pressure, geopotential heights, and measures of atmospheric moisture. Precipitation at a network of stations is modelled using tree-averaged multivariate copulas as outlined in Kirshner (2007). Detailed information on this version of the NHMM, including its mathematical parameterisations, estimation algorithms and assumptions can be found in Kirshner (2005) with a corresponding software toolkit available at: http://www.stat.purdue.edu/ skirshne/MVNHMM/.

The NHMM was calibrated using the period 1981-2000. This period was chosen due to its higher level of data quality control compared with earlier periods. Data spanning the period 1961-1980, of potentially lower quality, were reserved for cross-verification purposes. The NHMM was applied to the 4-month winter season, i.e. July-October. The model uses four weather states and four predictors: MSLP (mean sea level pressure), V700 (North-South wind at $700 \mathrm{hPa}$ ), Shum850 (specific humidity at $850 \mathrm{hPa}$ ), and DTD500 (dew point temperature depression at $500 \mathrm{hPa}$, i.e. the difference between air and dew point temperature). Prior to their use in NHMM calibration, the atmospheric predictors extracted from NNR were normalised. 


\section{RESULTS AND DISCUSSION}

\subsection{NHMM calibration results}

The NHMM model calibration results for 1981-2000 for the three data types are shown in Figure 3. The statistical downscaling of daily rainfall for the 38 stations gives the best correspondence between observed and simulated seasonal rainfall (Figure 3a). The method b) which treats each grid cell as an "observed" site consistently underestimates the seasonal rainfall (Figure 3b). The method c), i.e., to treat each sub-catchment as an "observed" site and calibrate to sub-catchment averaged rainfall, produce an acceptable result with slightly over-estimation (Figure 3c). Whether this result can be improved by increasing the wet-day threshold (currently $>=1 \mathrm{~mm}$ is used for all three data types) is the subject of further investigation. In all cases a more optimum combination of predictors could also potentially improve performance. The four predictors used were determined by 'manually building' models of greater complexity, i.e. starting with one predictor, then two, and so on. With greater computing power now available, future work will investigate all possible combinations of a larger set of candidate predictors.
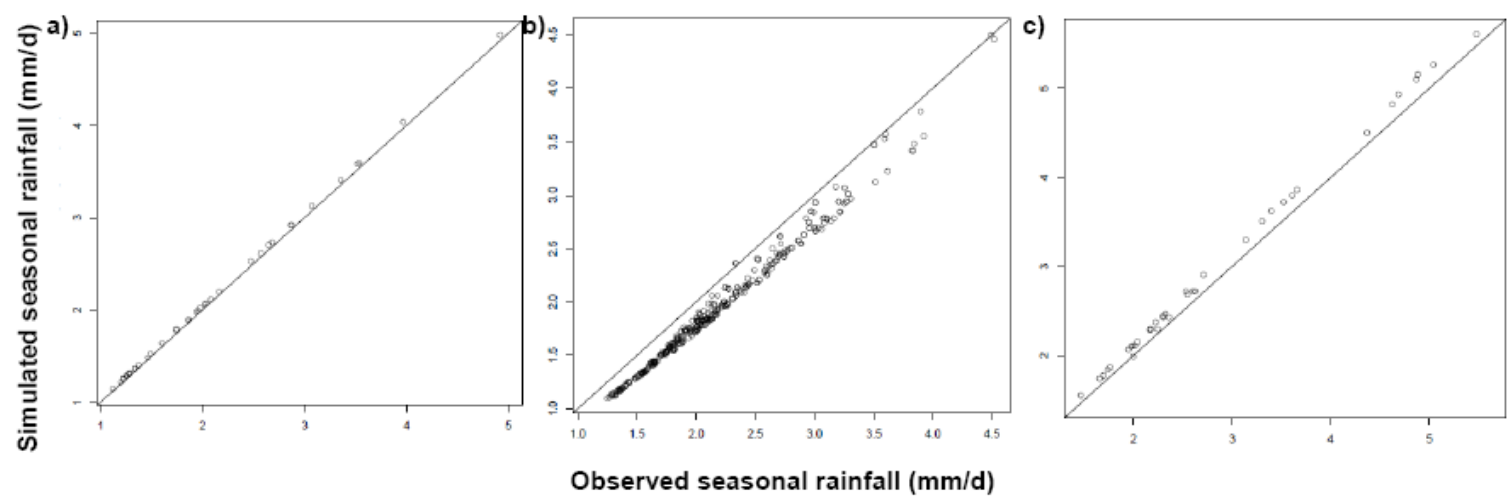

Figure 3 Comparison of observed and simulated seasonal rainfall for a) 38 stations, b) 364 grid cells, and c) 38 sub-catchments series for 1981-2000

\subsection{NHMM validation results}

The corresponding NHMM validation results for 1961-1980 for the three data types are shown in Figure 4. Generally there is less agreement between observed and simulated seasonal rainfall in comparison with the calibration period. Overall, the statistical downscaling of daily rainfall for the 38 stations still gives the best results (Figure 4a). The method b) consistently underestimates the seasonal rainfall, as was the case for the calibration period. Validation results for sub-catchment averaged rainfall produce a worse result with significant over-estimation (Figure 4c). Such biases could be a result of inadequate parameterizations of the NHMMs, non-stationarity in the relationship between NNR predictors and rainfall data, or data quality limitations, or some combination of all of these factors. Given that we do not know the extent to which the data quality of the station data used to construct the catchment rainfall and the reanalysis data used to drive
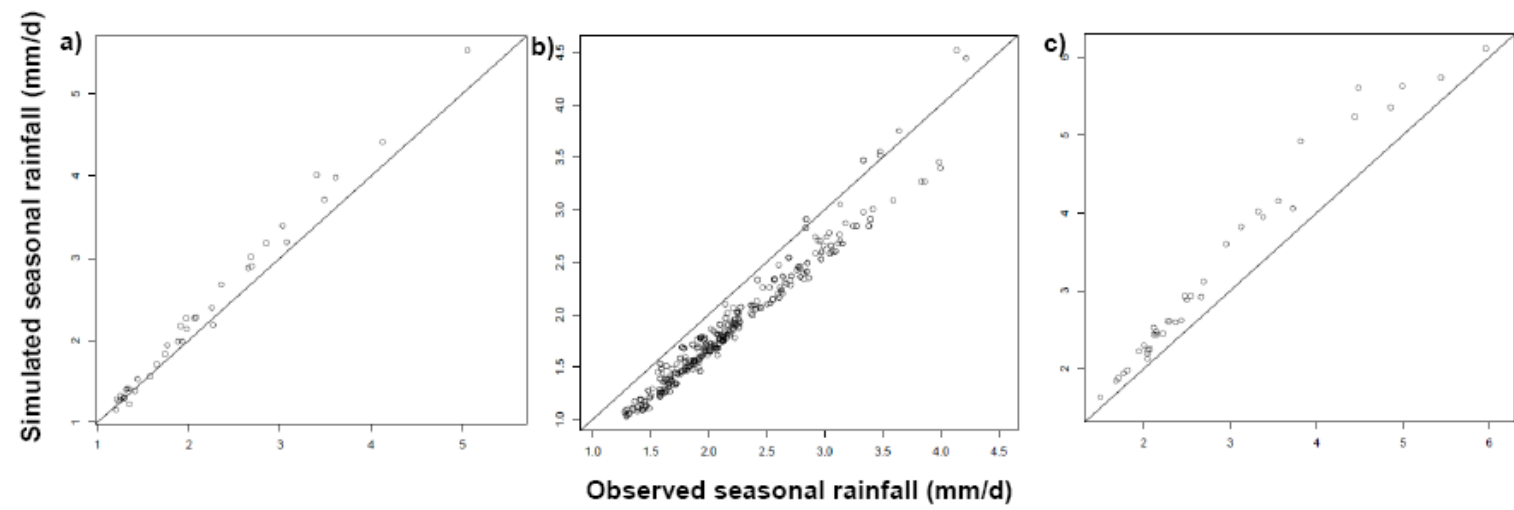

Figure 4 Comparison of observed and simulated seasonal rainfall for a) 38 stations, b) 364 grid cells, and c) 38 sub-catchments series for 1961-1980 
the NHMM is potentially worse in this earlier period, such a hypothesis is hard to test.

\subsection{Grid downscaling at sub-catchment scale}

To investigate whether the performance for gridded networks could be improved, 12 smaller-size subcatchments were selected for NHMM calibration (Figure 2). This investigated limitations in fitting the NHMM to highly correlated rainfall series. Rather than only fit 4 state models, as above, instabilities in model convergence required investigating 2, 3 and 4 state models for each sub-catchment. Table 1 indicates which model runs completed: 1) the NHMM only converged for 12 out of the 36 model runs attempted; we hypothesis that the highly spatial-correlated rainfall cells produce numerical instabilities in the NHMM algorithm; 2) within the 12 successful run scenarios, most of them could not produce an acceptable seasonal rainfall except in 3 or 4 cases (Figure 5) - catchment 405217 with 2 states, catchment 405269 with 2 states, catchment 405240 with 3 states, and (maybe) catchment 405240 with 4 states. This reflects the instability and suggests the unsuitability of the NHMM to downscale daily rainfall for the grid cells at a catchment scale.

Table 1. NHMM calibration success rates for 12 sub-catchments

\begin{tabular}{c|c|c|c|c}
\hline Catchments & Number of Grids & 2 States & 3 States & 4 States \\
\hline 405217 & 14 & $\mathrm{Y}$ & $\mathrm{Y}$ & $\mathrm{N}$ \\
405226 & 32 & $\mathrm{~N}$ & $\mathrm{~N}$ & $\mathrm{~N}$ \\
405228 & 20 & $\mathrm{~N}$ & $\mathrm{~N}$ & $\mathrm{~N}$ \\
405240 & 26 & $\mathrm{~N}$ & $\mathrm{Y}$ & $\mathrm{Y}$ \\
405269 & 49 & $\mathrm{Y}$ & $\mathrm{N}$ & $\mathrm{N}$ \\
406213 & 25 & $\mathrm{~N}$ & $\mathrm{~N}$ & $\mathrm{~N}$ \\
406224 & 11 & $\mathrm{~N}$ & $\mathrm{~N}$ & $\mathrm{~N}$ \\
407211 & 27 & $\mathrm{~N}$ & $\mathrm{~N}$ & $\mathrm{Y}$ \\
407215 & 41 & $\mathrm{~N}$ & $\mathrm{~N}$ & $\mathrm{~N}$ \\
407222 & 27 & $\mathrm{~N}$ & $\mathrm{Y}$ & $\mathrm{Y}$ \\
407236 & 65 & $\mathrm{Y}$ & $\mathrm{N}$ & $\mathrm{N}$ \\
408206 & 27 & $\mathrm{Y}$ & $\mathrm{Y}$ & $\mathrm{Y}$
\end{tabular}

\section{CONCLUSIONS}

This preliminary investigation has compared the suitability of the NHMM statistical downscaling model when calibrated to several daily rainfall data types, namely 1) meteorological station, 2) gridded and 3) catchment average daily rainfall data. Conclusions drawn from this assessment include:

- The best performance, of the methods compared, resulted from calibration to meteorological station data. The NHMM calibrated to 38 stations across the lower MDB reasonably reproduced the validation period mean rainfall characteristics.

- Calibration to catchment average rainfall, for a corresponding set of 38 sub-catchments, produced a reasonable calibration result but significantly more bias for the validation period in comparison with the station NHMM results. Whether the threshold used to define wet-days influences this aspect of performance will be investigated in future work.

- Calibration to all 364 grid cells across the study area catchments produced a biased result for both calibration and validation periods. Given this, subsequent analysis for 12 smaller sub-catchments produced mixed results given numerical instabilities in the NHMM optimization algorithms.

- It is difficult to determine the relative contribution to validation-period bias that could be the result of several factors, such as inadequate parameterizations of the NHMMs, non-stationary in the relationship between NNR predictors and rainfall data, or data quality limitations. Most probably all are involved to some extent, and so future work should also investigate validation issues.

\section{ACKNOWLEDEGMENT}

We would like to thank Dr Sergey Kirshner of Purdue University for developing the current version of the NHMM model and answering technical questions and Dr Lu Zhang of CSIRO Land and Water for project management. 
Fu et al., Statistical Downscaling of Daily Rainfall for Hydrological Impact Assessment
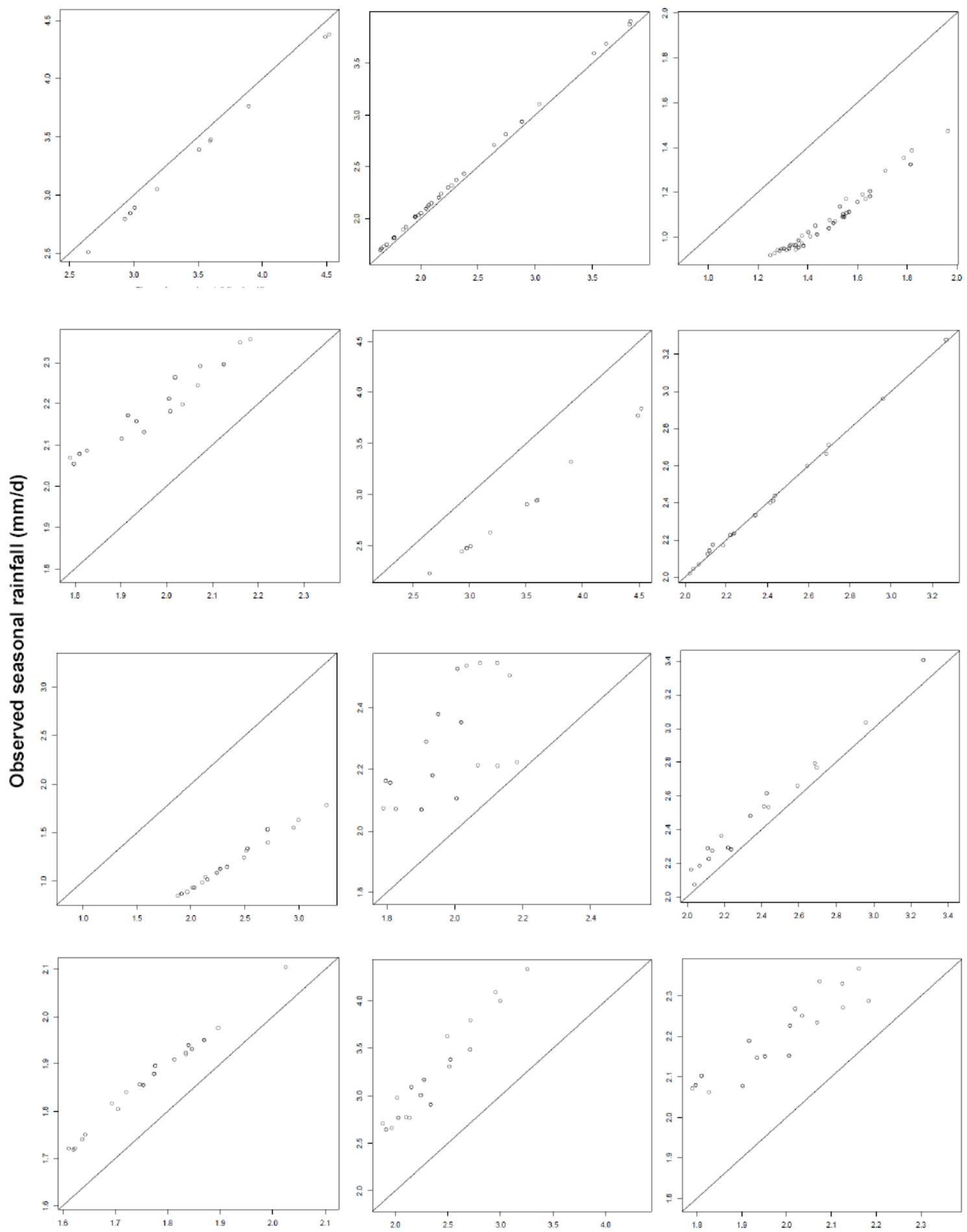

\section{Observed seasonal rainfall $(\mathrm{mm} / \mathrm{d})$}

Figure 5 Comparison of observed and simulated seasonal rainfall for 12 scenarios of Table 1

\section{REFERENCES}

Bates, B. C., Charles, S. P. \& Hughes, J. P. (1998) Stochastic downscaling of numerical climate model simulations. Environ. Model. Softw. 13(3-4), 325-331

Charles, S. P., Bates, B. C. \& Hughes J. P. (1999) A spatio-temporal model for downscaling precipitation occurrence and amounts. J. Geophys. Res. - Atmospheres 104(D24), 31657-31669. 
Fu et al., Statistical Downscaling of Daily Rainfall for Hydrological Impact Assessment

Charles, S. P., Bates, B. C., Smith, I. N. \& Hughes, J. P. (2004). Statistical downscaling of daily precipitation from observed and modelled atmospheric fields. Hydrol. Processes 18(8), 1373-1394

Chiew, F.H.S. (2006), Estimation of rainfall elasticity of streamflow in Australia, Hydrol. Sci. J., 51, 613625.

Christensen JH, Hewitson B, Busuioc A, Chen A, Gao X, Held I, Jones R, Kolli RK, Kwon WT, Laprise R, Magaña Rueda V, Mearns L, Menéndez CG, Räisänen J, Rinke A, Sarr A, Whetton P. 2007. Regional Climate Projections. In: Climate Change 2007: The Physical Science Basis. Contribution of Working Group I to the Fourth Assessment Report of the Intergovernmental Panel on Climate Change. Cambridge University Press: Cambridge.

Frost, A. J., Charles, S. P., Timbal, B., Chiew, F. H. S., Mehrotra, R., Nguyen, K. C., Chandler, R. E., McGregor, J. L., Fu, G., Kirono, D. G. C., Fernandez, E. \& Kent, D. M. (2011) A comparison of multisite daily rainfall downscaling techniques under Australian conditions. J. Hydrol. in press, doi:10.1016/j.jhydrol.2011.06.021

Fu, G.B., S. P. Charles, and F. H. S. Chiew, 2007a: A two-parameter climate elasticity of streamflow index to assess climate change effects on annual streamflow. Water Resour. Res., 43, W11419, doi:10.1029/2007WR005890.

Fu, G.B., S. P. Charles , 2011, Statistical downscaling of daily rainfall for southeastern Australia. In: Hydroclimatology: Variability and change (Proceedings of symposium JH02 held during IUGG2011 in Melbourne, Australia, July 2011), IAHS Publ. 344, 69-74.

Hofstra, N., M. Haylock, M. New, P. Jones, and C. Frei (2008), Comparison of six methods for the interpolation of daily, European climate data, J. Geophys. Res., 113, D21110, doi:10.1029/2008JD010100

Hughes, J. P., Guttorp, P. \& Charles, S. P. (1999) A non-homogeneous hidden Markov model for precipitation occurrence. J. Royal Stat. Soc., Series C-Applied 48(1), 15-30.

Jeffrey S.J., Carter J.O., Moodie K.B., Beswick A.R., 2001. Using spatial interpolation to construct a comprehensive archive of Australian climate data. Environmental Modelling and Software 16:309330.

Kirshner, S. (2005) Modeling of multivariate time series using hidden Markov models, 202 pages, PhD Thesis. University of California, Irvine, USA. ISBN:0-496-98673-2

Kirshner, S. (2007) Learning with tree-averaged densities and distributions, Advances in Neural Information Processing Systems, NIPS 2007, December 2007

Kundzewicz, Z.W. et al. (2007). Freshwater resources and their management. In: Climate Change 2007: Impacts, Adaptation and Vulnerability. Contribution of Working Group II to the Fourth Assessment Report of the Intergovernmental Panel on Climate Change [M.L. Parry et al. Eds."]. Cambridge University Press, Cambridge.

Maraun, D., et al. (2010) Precipitation downscaling under climate change: Recent developments to bridge the gap between dynamical models and the end user. Rev. Geophys. 48, RG3003, doi:10.1029/2009RG000314.

Meehl, G.A. et al. (2007) Global Climate Projections. In: Climate Change 2007: The Physical Science Basis. Contribution of Working Group I to the Fourth Assessment Report of the Intergovernmental Panel on Climate Change [Solomon, S., D. Qin, M. Manning, Z. Chen, M. Marquis, K.B. Averyt, M.Tignor and H.L. Miller (eds.)]. Cambridge University Press, Cambridge.

Potter N. J., Chiew, F. H. S. \& Frost, A. J. (2010) An assessment of the severity of recent reductions in rainfall and runoff in the Murray-Darling Basin. J. Hydrol. 381, 52-64.

Viney NR, Bates BC (2004) It never rains on Sunday: the prevalence and implications of untagged multi-day rainfall accumulations in the Australian high quality data set. Int J Climatol 24:1171-1192 